\title{
Discourse prosody and political speech in Greek
}

Anthi Chaida, Aikaterini Bakakou-Orphanou, Nafsika Dokou, Anna Kouvela Laboratory of Phonetics \& Computational Linguistics, University of Athens, Greece https://doi.org/10.36505/ExLing-2012/05/0010/000216

\begin{abstract}
This is a study of the prosodic characteristics of discourse, based on the analysis of a TV interview of a Greek politician. Temporal and tonal features were examined. It is shown that breaks and pauses cut up sentences into smaller chunks, which reflect semantic and discourse functions rather than syntactic structures. The politician did not use rising tonal structures at phrase boundaries in most cases, deviating from an average speaker. The issue of how "professional" public speakers differentiate their use of prosodic means by adopting more stereotyped patterns is, thus, raised.
\end{abstract}

Key words: discourse, prosody, intonation, political speech, Greek.

\section{Introduction}

This study focuses on prosodic structure and discourse organisation, reporting on an analysis of spontaneous speech material by a well-known Greek politician, who is considered to be a skilled speaker.

Prosody conveys various discourse functions, interacting with linguistic factors and is assumed to express "the meaning" of a message (e.g. Wichmann, 2002). It has been suggested that a prosodic grammar interacts with linguistic and rhetorical features, in order to build an argumentative discourse, a "prosodic code" (Braga \& Marques, 2004). Prosodic elements are intentionally manipulated in correlation with syntactic, lexical and pragmatic ones. In many languages, including Greek, intonation sets boundaries of speech units and brings forth the material they are aligned with into information units, with phrasing and prominence, according to the speaker's intention for the listener's interpretation (e.g. Botinis, 1995; Martin, 2010). Prosodic parameters, such as intonation, speech rate and intensity, are also essential for characterising a "good speaker" (Strangert \& Gustafson, 2008), as well as emotions and expressions (Wichmann, 2002).

In political speech, the art of persuasion involves a dual transaction: an audience to be persuaded and a persuader with a target-oriented rhetoric (Touati, 1993). It is assumed that persuasive political discourse typifies the speaking style, while "intensifiers" are often used to highlight several elements of the argumentation by tonal and temporal means (Touati, 1993; Strangert, 2005; Martin, 2010).

\section{Methodology}

The speech material consists of an interview of a male Greek politician, within a TV news report. The whole interview is $4.36 \mathrm{~min}$

ExLing 2012: Proceedings of 5th Tutorial and Research Workshop on Experimental Linguistics, 27-29 August 2012, Athens, Greece 
long, while the examined part of the politician's speech is $1.59 \mathrm{~min}$ (95.16 sec) long. A part of the interviewer's speech (newscaster) was also analysed ( $\sim 34.42 \mathrm{sec}$, control sample). The interview is about the economic policy, focusing on the government's measures on taxing and pension. Both speakers are in their fifties, with standard Athenian pronunciation. The recorded material was written in standard Greek spelling and segmented into perceived phrases.

Acoustic analysis was carried out with Praat and statistics with StatView. Duration measurements were taken for pauses and phrase length (chunks). F0 was taken for pre/post-break pitch (phrasing), mean F0, and tonal range of the whole of each speech sample.

\section{Results}

The main variables measured in the politician's speech sample are presented in Table 1. The pause-to-speech ratio is relatively low (21\%), considering that the interview was produced without any manuscript. Pauses (silent intervals) are many, but generally fairly short (mean duration $245 \mathrm{~ms}$, sd=154), contributing to the low pause-to-speech ratio.

Breaks and pauses cut up sentences into smaller chunks, reflecting semantic rather than syntactic structuring. There are many cases where perceived breaks in prosodic phrases do not involve pauses. Longer pauses occur after no syntactic phrase (no), i.e. after particles and conjunctions. Pauses occur after sentences (clause), subordinate clauses (secondary clause), and other syntactic phrases (phrase, e.g. prepositional phrase, adjunctive phrase in genitive) - with this order, longest to shortest (Fig. 1). Pause length as a function of syntactic phrases is not significant for any pair (post-hoc test).

Chunks with 2-4 words are the most frequent, but single-word chunks are also noted. Mean phrase length in the politician's speech sample is 1607 $\mathrm{ms}$, and $1162 \mathrm{~ms}$ in the interviewer's (Fig. 2), with a significant difference $(\mathrm{t}(\mathrm{df} 82)=3.003, \mathrm{p}<0.05)$.

With regards to intonation and syntactic phrases (Fig. 3), it seems that sentences (clause) are more prominently indicated by tonal means, in the politician's sample. However, the interaction of syntactic phrases with pitch is not statistically significant, either in pre-break $(F(3,63)=0.86$, $\mathrm{p}=0.46)$, or in post-break position $(\mathrm{F}(3,63)=1.42, \mathrm{p}=0.26)$.

Regarding prosodic phrasing, the politician does not use rising tonal boundaries at phrase breaks in most cases. In his sample (Fig. 4), pre-break pitch (mean $173 \mathrm{~Hz}$ ) is quite lower than post-break (mean 204 $\mathrm{Hz})$, with a significant difference $(\mathrm{t}(\mathrm{df} 66)=-3.98, \mathrm{p}<0.05)$. In contrast, the interviewer's sample shows similar tonal features to usual spontaneous speech phrasing, with rising boundary at phrase breaks: pre-break pitch (mean $161 \mathrm{~Hz}$ ) is higher than post-break (mean $153 \mathrm{~Hz}$ ), a not significant difference though $(\mathrm{t}(\mathrm{df} 16)=0.43, \mathrm{p}=067)$. The difference between the two speakers is not significant for pre-break pitch $(\mathrm{t}(\mathrm{df}$ $82)=-0.69, \mathrm{p}=0.49)$, but it is highly significant for post-break $(\mathrm{t}(\mathrm{df} 82)=-5.20$, $\mathrm{p}<0.001$ )(see Fig. 5-6). 
Table $1 . \mathrm{F} 0$ and duration data for the speech sample by the Greek politician.

Politician's speech

\begin{tabular}{ll|lc}
\hline F0 $(\mathrm{Hz})$ & & Duration $(\mathrm{sec})$ & \\
Mean & 208.63 & Total speech sample & 95.16 \\
Standard deviation & 39.68 & Total pauses & 16.44 \\
Minimum & 75.26 & Mean pause & 0.24 \\
Maximum & 317.97 & Pause-to-speech ratio & $21 \%$ \\
Tonal range & 242.71 & & \\
\hline \hline
\end{tabular}
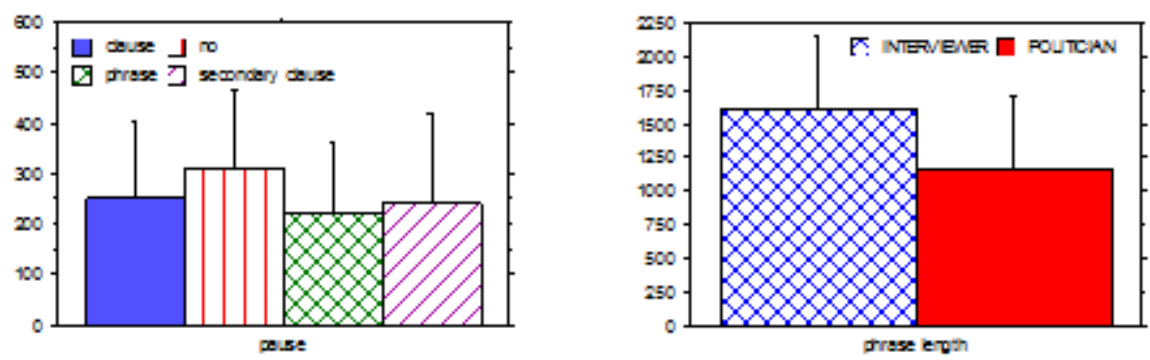

Figure 1: Mean pause duration (ms) Figure 2: Mean phrase length (ms) of of the politician speech, with regards the politician speech sample in to syntactic phrases. comparison to the interviewer's.
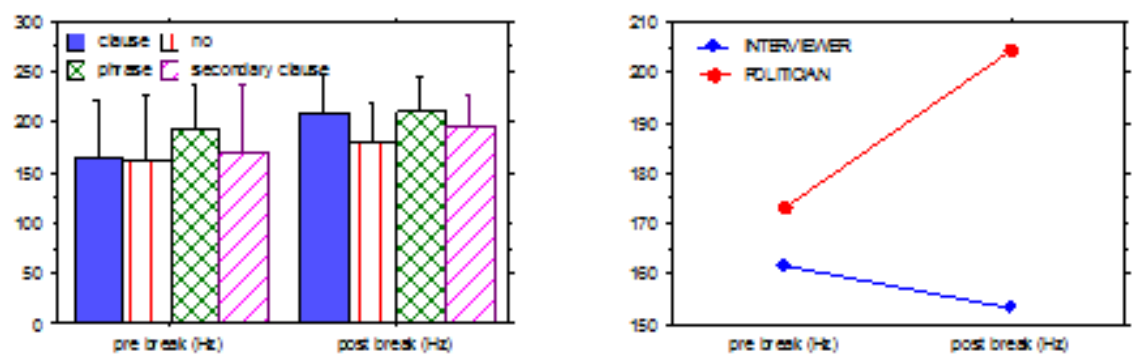

Figure 3: Mean pre- and post-break Figure 4: Mean pre- and post-break pitch $(\mathrm{Hz})$ of the politician's sample, with regards to syntactic phrases. pitch $(\mathrm{Hz})$ of the politician's sample in comparison to the interviewer's.
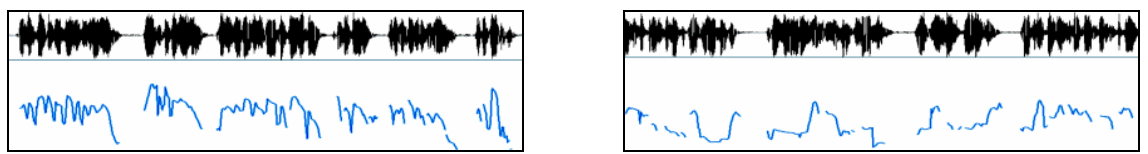

Figure 5-6: Pitch snapshots by the politician's (left) and the interviewer's (right) speech sample. 


\section{Discussion and conclusions}

Prosody plays a significant role with respect to discourse functions of political speech. Pauses were short and frequent. Chunks were short, with breaks occurring regardless of syntactic structures, violating continuity. Breaks were used in most cases in non-syntactic positions, demonstrating a sort of "semantic pausing" (Strangert, 2005). In fact, pauses in non-syntactic positions were longer than pauses based on syntactic structures, denoting that they are functional and intentional. Thus, breaks in non-syntactic positions may be considered as means to emphasise parts of speech, within the persuasive purposes of the speaker, although they might also indicate discourse processing by the speaker, since in spontaneous speech there is no time for planning what to say next. Producing breaks in non-expected positions can be seen as an attempt by the speaker to avoid interruptions (Strangert, 2005).

The politician uses a variety of argumentative and expressive acts, as well as strategies exploiting tonal prominence and phrasing (Botinis, 1994, 1995). However, his speech seems to differ from a non-skilled speaker, with respect to prosodic phrasing. He used consistently falling tonal contours, without exploiting "colourful" means for tonal segmentation ("tonal disjunction/conjunction" archetypes in Botinis, 1994). This is an interesting finding, maybe denoting "typification" of political speech (also found in Ségolène Royal's speech data, reported in Martin, 2010). This constant use of falling tonal patterns in discourse phrases does not probably serve well the persuasion purposes of a politician, while it typically puts the audience at a distance.

\section{References}

Botinis, A. 1994. Tonal segmentation and tonal binding in discourse interpretation. FONETIK 94. Working Papers 42, 24-27, Lund University.

Botinis, A. 1995. Tonal correlates of discourse structure. $13^{\text {th }}$ International Congress of Phonetic Sciences, Stockholm, Sweden, 1995.

Braga, D., Marques, M.A. 2004.The pragmatics of prosodic features in the political debate. Speech Prosody, Nara, Japan, 2004.

Martin, P. 2010. Intonation in political speech: A comparison between Ségolène Royal and Nicolas Sarkozy intonation. International Workshop in "Political Speech (Il Parlato Politico)", Rome, Italy, 2010.

Strangert, E., Gustafson, J. 2008. What makes a good speaker? Subject ratings, acoustic measurements and perceptual evaluations. Interspeech, Brisbane, Australia, 2008.

Strangert, E. 2005. Prosody in public speech: analyses of a news announcement and a political interview. Interspeech, Lisboa, Portugal, 2005.

Touati, P. 1993. Prosodic aspects of political rhetoric. ESCA Workshop on Prosody, Working Papers, 41, 168-171, Lund University.

Wichmann, A. 2002. Attitudinal intonation and the inferential process. Speech Prosody, Aix-en-Provence, France, 2002. 